\title{
Shapley value based transfer pricing in supply chains with stochastic demand
}

\author{
Lihua Chen*
}

Gary E. West College of Business, West Liberty University, 208 University Drive, West Liberty, WV 26074, USA

\section{H R O N I C L E}

Article history:

Received July 14, 2014

Accepted August 7, 2014

Available online

August 92014

Keywords:

Optimization

Game theory

Stochastic demand

\begin{abstract}
A B S T R A C T
We study the question of how to ideally divide total profits among supply chain members, especially in a stochastic demand market. The Shapley value is used as the methodology solution to divide profits in a supply chain. To illustrate the Shapley value solution and procedures, a two-echelon supply chain consisting of one supplier and two heterogeneous retailers is examined. The goal is to figure out ideal transfer prices for products delivered among supply chain members. These transfer prices will achieve the suggested profit allocations among three companies.
\end{abstract}

C 2015 Growing Science Ltd. All rights reserved.

\section{Introduction}

Recently, supply chain management research has stressed the importance of coordination in decentralized supply chains (e.g., Corbett et al., 2004; Cachon \& Lariviere, 2001; Bernstein \& Federgruen, 2005). Supply chain coordination helps create more streamlined business processes and enables cost reduction. It has been shown that supply chain members are not primarily concerned about the supply chain total profits, but about their individual profits (e.g., Cachon, 1999; Fransoo et al., 2001). It is critical for each supply chain member to achieve a certain level of profits to insure supply chain coordination. Supply chain coordination is a series of activities, which are taken by independently managed parties in a supply chain to act in the same way as operated by one single decision maker. It often leads to global cost reduction, higher service levels, a reduction of the bullwhip effects, better resource utilization and effective market demand responses. One critical question in coordinating a decentralized supply chain is how to price products shipped between supply chain members. Normally, supply chain members will sign contracts to reach agreements which determine profits from transactions. Cachon (2003) demonstrated that a lot of incentive contracts could coordinate supply chains. In order to implement an incentive contract, agreements regarding the profit allocation scheme must be reached before the realization of supply chain demand. The goal of this paper is to figure out ideal transfer prices for products delivered between supply

* Corresponding author. Tel: +1-304-336-8537

E-mail address: Lihua.chen@westliberty.edu (L. Chen) 
chain members. The role of transfer prices as a coordinating mechanism has been explored for this problem (e.g., Yeom \& Balachandran, 2000). Despite the extensive literature, transfer pricing remains a complex problem in a stochastic demand market. Both revenue and costs are always jointly necessary for a comprehensive description and analysis of supply chain transfer pricing.

The objective of the research presented herein is to explore fair sharing of revenue and costs among supply chain members in a stochastic demand market. A two-echelon supply chain will be examined consisting of one supplier and two heterogeneous retailers; each company is an autonomous profitgenerating entity. Each retailer faces a stochastic demand. In particular, the role of transfer prices in supply chain coordination is considered. The transfer price is a term that is generally used by divisions affiliated to the same organization to denote product/service unit price of intra-company transactions (Vaysman, 1998). However, the terminology has also been extended to refer to payments among companies that are not affiliated with one organization, e.g., decentralized supply chain members (e.g., Gjerdrum et al., 2002; Vidal \& Goetschalckx, 2001). A value-sharing method based on the Shapley value from the cooperative game theory is proposed to determine transfer prices of delivered products among supply chain members. The Shapley value solution is an appealing allocation rule since it takes into account the potential payoff from alternative options. The Shapley value of each player is partially determined by how much the player can get by remaining independent from the grand coalition. It assigns a higher payoff to players who contribute more to the grand coalition. Once reached, such an agreement could simplify the process of bargaining on transfer prices which embody fairness. Rosenthal (2008) calculates transfer prices in a vertically integrated supply chain, where supply chain members share technology and transaction costs. A limitation of Rosenthal's work (2008) is the assumption of deterministic demand. This paper study a supply chain facing stochastic demands and establish a division scheme of profits.

The remainder of the article is organized as follows. In Section 2, the core and the Shapley value are introduced, followed by a review of current research of the Shapley value solution over supply chain management in Section 3. Then methodologies and numerical examples are presented in Section 4. In Section 5, a summary and conclusion are taken to discuss the contribution and future studies.

\section{The core and the Shapley value}

Both the core and the Shapley value are commonly used in cooperative games, where the players are allowed to form binding agreements. The core and the Shapley value are two alternative solution concepts to divide the total payoff among all players in cooperative games. If and only if the core is nonempty, the grand coalition will form; while the Shapley value offers a fair solution to the division of profits (costs) of the grand coalition. In a coalition game, a unique payoff vector can be reached through the Shapley value.

A cooperative game is a pair $(N ; v)$, where $N$ is the set of players and $v: 2^{N} \rightarrow \mathfrak{R}$ is the characteristic function. Any subset $S$ of $N$ is called as a coalition, and $v(S)$ is the worth of $S$. For any coalition $S \subset N$, the number of players in $S$ is denoted by $|S|$. A characteristic function $v$, defined on all subsets of $N$, is a real-valued function that shows the amount of payoff received by the players in the coalition $S$. By definition, $v(\varnothing)=0$. For game $(N ; v), x_{i}(v)$ is an allocation function that is used to assign a payoff of $x_{i}$ to player $i$ in $N$. Assuming that $N$ represents the grand coalition, an allocation $x_{i}$ is in the core of game $v$ if and only

$$
\sum_{i \in N} x_{i}=v(N) \quad \text { and } \quad \sum_{i \in S} x_{i} \geq v(S)
$$


for any $S \subseteq N$. A core allocation divides the total payoff of the grand coalition among all the players, and the sum of the payoffs to the players of each coalition $S$ is no less than the payoff of the coalition $S$. With an allocation in the core of a game, no coalition has an incentive to quit from the grand coalition $N$ since leaving the grand coalition will cause it to get less. However, the core of a cooperative game may be empty. So what conditions on game $v$ guarantee the core is not empty? One of the early answers was presented by Shapley (1971) by showing that for a convex game, the core is not empty. In a convex game, the Shapley value allocation is an element of the core (Shapley, 1971).

The Shapley value is an expected payoff to player $i, \phi_{i}(v)$, which is the only solution that satisfies the four axioms below (Shapley, 1953).

1) The first axiom is the symmetry axiom. This axiom illustrates that players would be assigned the same value if they are treated identically by the characteristic function. 2) The second axiom, named as the efficiency axiom, states that the sum of $\phi_{i}(v)$ over all players is equal to $v(N)$. This axiom implies that the Shapley value assigns the total value of the coalition to the players in $N .3$ ) The third axiom is the dummy axiom. If $v(S \cup i)=v(S)$ for all $\mathrm{S}$, then player $i$ must get zero. 4) The last axiom, called as the law of aggregation, requires that if we combine two games described by characteristic functions $v$ and $w$, then $\phi_{i}(v+w)=\phi_{i}(v)+\phi_{i}(w)$ for any player $i$ in $N$. It shows that the total Shapley value of two games $v$ and $w$, which are played at the same time, equals to the sum of the Shapley value when the player plays the game $v$ and $w$ at different times.

The Shapley value $\phi_{i}$ is defined by the following formula

$\phi_{i}(v)=\sum_{S \subseteq N \backslash\{i\}} \frac{(s) !(n-s-1) !}{n !}[v(S \cup i)-v(S)]$

In Eq. (2), the term $[v(S \cup i)-v(S)]$ represents the contribution of the player $i$ joining $S$. The fractional term, $\frac{(s) !(n-s-1) !}{n !}$, indicates the probability that a coalition $S$ is already formed before player $i$ joins $S$. Therefore, player $i$ will have a Shapley value that is the expected sum of all the incremental values resulting from the player joining $S$ weighted with the probabilities of the player joining the respective coalition.

\section{The application of the Shapley value in supply chain management}

Lately, the Shapley value has been used in a few supply chain management papers as a solution methodology. For example, Bartholdi and Kemahlioğlu-Ziya (2005) used the Shapley value to allocate supply chain savings, which result from inventory pooling for all of the parties in a supply chain. Feess and Thun (2014) applied the Shapley value to divide surplus to analyze investment incentives. Granot and Sošić (2003) found a fair allocation scheme for the maximal residual profits among multiple retailers by the Shapley value. In a following study by Sošić (2006), the Shapley value is again used to distribute profits from residual inventory transshipment among farsighted retailers. A 'farsighted' retailer would consider both his actions and how other retailers would react to his actions. It turns out that the profits from residual inventory transshipment would be always maximized under the Shapley value allocation. Robinson (1993) reexamined a cooperative game initially presented by Gerchak and Gupta (1991). He used the Shapley value to allocate a fair cost sharing among a number of retailers, each of them facing random demands. But these retailers have a continuous-review single-period inventory model with full back ordering. Robinson (1993) then presented a cost allocation scheme based on the Shapley value that made every retailer better off and 
considered the allocation of costs among only retailers. All of these papers examine a different division problem, since we study a supply chain consisting of both retailers and supplier and explore revenue and cost allocation scheme with stochastic demand.

Additionally, the Shapley value has been used to divide profits of supply chains in a couple of papers. Manes and Verrecchia (1982) applied both the Massachusetts formula (MF) and the Shapley value adjusted MF to set intra-company transfer prices. One limitation of this model is that it only studies a constant product flow. In the existing literature, the closest research to our work was done by Rosenthal (2008), where a cooperative game is set up among all divisions in a vertically integrated supply chain and a procedure is provided to obtain transfer prices between divisions using the Shapley value. In Rosenthal (2008)'s model, a division sells a certain amount of products to its downstream division and the profits are allocated among all upstream divisions in the supply chain. With subadditive coalition cost functions, the game between divisions is shown to be a convex game, where the core of the game exists and the Shapley value of the game is the centroid of the core. One limitation of this model is that, as mentioned, it does not consider varying demands. Furthermore, the author did not aim to explain what would occur from the decision maker's selection of different transfer prices within the range, wherein each set of values provides stable outcomes of the game.

\section{Methodology}

\subsection{Model assumptions}

The purpose of the methodology section is to develop a sequence of mathematical models to compute transfer prices among supply chain members. In this paper, we investigate a decentralized supply chain with one supplier and two heterogeneous retailers (denoted by $R_{0}, R_{1}$, and $R_{2}$, respectively). The two retailers are in different and independent markets and may purchase from any supplier, including $R_{0}$. The supplier can sell to $R_{1}, R_{2}$ or elsewhere. In the beginning, the three companies have transactions but without any agreements. From the transaction history, the wholesale price of $R_{0}, p_{0}$, retail price per unit product of $R_{1}, p_{1}$, and retail price per unit product of $R_{2}, p_{2}$, are all public information. Basically, these prices are current market prices and can be used as benchmarks for transfer prices. Furthermore, the demand information can be acquired from retailers' records. The demand can be affected by seasonality, substituted product promotion, product retail price, etc. However, it is possible that there is a fluctuating tendency resulting from more than retail prices. We assume that demand distribution is following a certain stochastic functions, but not a function of retail price. Letting demand be a function of only retail price will be a leftover research question for future study. The next step is to figure out the transfer prices among supply chain members if they form a coalition and make a transaction in one time period with one single order. In the game of $R_{0}, R_{1}$, and $R_{2}$, the characteristic function $v(S)$, where $v: 2^{N} \rightarrow \Re$, is defined as the worth of the coalition $S$. When the grand coalition is formed complete information can be further assumed: each player knows about the cost information of the other players in the coalition - including purchase cost, holding cost, shortage cost, fixed cost (e.g., technology and transactions cost) etc., and revenue information. In the grand coalition, the profit generated from sales by the two retailers is to be allocated among the three players. Since the objective is to divide the total profits of the grand coalition among the three players, we will only prove that the grand coalition is stable. Not as in the literature of coalition structure (Owen, 1977; Hart, \& Kurz, 1983; Casajus, A., 2009), we do not study whether all of the coalitions in the game will form or not. The "worth"s of these coalitions are calculated for the application of the Shapley value if these coalitions form. We know that normal demand functions are widely used in the literature (e.g., Gerchak \& Gupta, 1991; Cachon, 2003). Then let $R_{1}$ 's demand be normally distributed with density function $f_{1}(d), R_{2}$ 's demand be normally distributed with density function $f_{2}(d)$, and $f_{1}(d) \neq f_{2}(d)$. The two retailers remain independent, and their total demand is 
still normal. Both retailers order a certain amount of products from the supplier to fulfill their own stochastic demand. It is assumed that if the two retailers form a coalition, they will share a common warehouse and the common unit holding cost is less than either individual unit holding cost $\left(h<h_{i}\right.$, $i=1,2$ ). The retail price $p_{i}$ is determined by each retailer. The supplier sells a common product to two retailers at a wholesale price $p_{0}$ with $c_{0}<p_{0}<p_{i}$, whereby $i=1,2$, and $c_{0}$ is the manufacturing cost per unit of $R_{0}$. It is interesting to figure out how much the transfer price should be if the retailers and the supplier form an alliance. Transfer prices are the sale prices among all three players when they cooperate. In this paper, a wholesale price denotes the market price charged by the supplier to a retailer without any agreement between them. The transfer price herein is the unit payment between the supplier and a retailer within a coalition. It should be made clear that with a cost saving coalition ( $B_{G}<B_{0}+B_{12}<B_{0}+B_{1}+B_{2}$ ), the transfer price is very likely different from the wholesale price to indicate a relatively fair profit allocation. The supplier has enough capacity to satisfy orders from the two retailers --- no capacity constraints. The firms are in one country, without tax rate difference. Following the assumption by Rosenthal (2008), transactions between the supplier and a retailer could save some fixed cost as compared with the case without any agreement. So do holding costs. Cost functions are accordingly subadditive. The models that we are going to present are newsvendor models in a single time period with one order (no repeating orders). Furthermore, except the grand coalition, those coalitions do not really occur, but occur theoretically. For example, retailers do not truly pool stock to reduce variance, but theoretically it could be figured out how much contribution and benefits each retailer will have if they order together.

\subsection{Notations}

Parameters:

$f_{i}(d)$ : Demand density function of retailer $i(i=1,2)$

$D_{i}$ : Demand of retailer $i(i=1,2)$ (units)

$Z$ : The total demands of the two retailers (units)

$g(z)$ : Probability density function of the two retailers' total demand

$B_{i}$ : Fixed cost of retailer $i(i=1,2)$ per order ( /order)

$h_{i}$ : Unit holding cost of retailer $i(i=1,2)$ ( / unit)

$h$ : Unit holding cost of retailers if the two retailers form a coalition ( /unit)

$\eta_{i}$ : Unit shortage cost of retailer $i(i=1,2)$ ( / unit), where $\eta_{i}>h_{i}$

$p_{0}$ : The wholesale price of $R_{0}$ ( / unit)

$p_{1}$ : $\quad$ Retail price per unit product of $R_{1}$ ( / unit), where $p_{1}>p_{0}$

$p_{2}: \quad$ Retail price per unit product of $R_{2}$ ( / unit), where $p_{2}>p_{0}$

$B_{0}$ : $\quad$ Fixed cost of $R_{0}$ per order from $R_{1}$ or $R_{2}$ ( /order)

$c_{0}$ : Manufacturing cost per unit of $R_{0}$ ( / unit), where $c_{0}<p_{0}$

$B_{01}$ : Fixed cost per order if $R_{0}$ and $R_{1}$ make a coalition ( /order)

$B_{02}: \quad$ Fixed cost per order if $R_{0}$ and $R_{2}$ make a coalition ( /order)

$B_{12}$ : $\quad$ Fixed cost per order if $R_{1}$ and $R_{2}$ make a coalition ( /order)

$B_{G}: \quad$ Fixed cost per order of the grand coalition ( /order)

$B^{G}$ : Fixed cost of player $i$ per order in the grand coalition $(i=0,1,2)$ ( /order)

Variables:

$q_{i}$ : Order quantity of retailer $i(i=1,2)$ (units) 
$q_{i}^{G}:$ Order quantity of retailer $i$ if the grand coalition forms

Dependent variables:

$\pi_{i}$ : Expected profit of player $i(i=0,1,2)$

$\pi_{0_{1}}$ : Expected profit of $R_{0}$ resulting from transactions with $R_{1}$

$\pi_{0_{2}}$ : Expected profit of $R_{0}$ resulting from transactions with $R_{2}$

$\pi_{i j}$ : Total expected profits of the coalition composed of $R_{i}$, and $R_{j}(i, j=0,1,2 ; i \neq j)$

$\pi_{G}$ : Total expected profits of the grand coalition

$\pi_{i}^{G}$ : Expected profit of player $i(i=0,1,2)$ if the grand coalition forms but before transfer prices are paid

$T P_{i}$ : The transfer price between $R_{0}$ and $R_{i}$ when $R_{0}, R_{1}$, and $R_{2}$ form a coalition. $T P_{i}>0(i=1,2)$ denotes a net payment from retailer $i$ to the supplier, while $T P_{i}<0 \quad(i=1,2)$ denotes an opposite payment from the supplier to retailer $i$ ( / unit)

\subsection{Model development}

In this three-player game, there are seven possible coalitions, $S \in\left\{\left\{R_{0}\right\},\left\{R_{1}\right\},\left\{R_{2}\right\},\left\{R_{0}, R_{1}\right\}\right.$, $\left.\left\{R_{0}, R_{2}\right\},\left\{R_{1}, R_{2}\right\},\left\{R_{0}, R_{1}, R_{2}\right\}\right\}$. The analysis proceeds as follows. First, determine coalition $S$ 's worth, $v(S)$. In this supply chain, $v(S)$ is simply the coalition' expected profits, $\pi_{S}$. Such profit levels are well-defined as shown in the following subsections. Note that for a coalition consisting of one player, the coalition's worth is equal to this player's profit when all three players remain independent. Second, calculate the Shapley value using Eq. (2). Finally, use retailer $i$ 's Shapley value to calculate the transfer price paid to the supplier by retailer $i$. Indeed, to determine the transfer prices paid by the two retailers, it is assumed that the grand coalition forms and that each player earns a payoff equal to its Shapley value from game $(3 ; v)$. More specifically, for game $(3 ; v)$, retailer $i$ 's transfer price is defined as $T P_{i}=\frac{\pi_{i}^{G}-\phi_{i}}{q_{i}^{G}}(i=1,2)$.

Calculating transfer prices requires an additional step because $\pi_{i}^{G}$ is not well-defined. Indeed, to characterize $\pi_{i}^{G}$, the fixed cost of the grand coalition must be allocated to the three players. For consistency, we assume that the Shapley value is used as the fixed cost allocation rule. In this game, each coalition's worth is the fixed cost it would incur if that coalition were to form. For the sake of clarity, it will be shown that in a fully coordinated supply chain consisting of three players (i.e., one that plays the cooperative game $(3 ; v)$ and uses the transfer prices defined above), each player does earn its Shapley value as expected payoff. Then retailer $i$ 's expected payoff is just $\phi_{i}(v)$. Meanwhile, the amount transferred to the supplier via transfer prices is

$\left(T P_{1}\right)\left(q_{1}^{G}\right)+\left(T P_{2}\right)\left(q_{2}^{G}\right)=\pi_{1}^{G}-\phi_{1}+\pi_{2}^{G}-\phi_{2}$.

Hence

$\left(T P_{1}\right)\left(q_{1}^{G}\right)+\left(T P_{2}\right)\left(q_{2}^{G}\right)=\pi_{G}-\pi_{0}^{G}-\left(\pi_{G}-\phi_{0}\right)=\phi_{0}-\pi_{0}^{G}$.

But since in the grand coalition, the supplier's only source of revenue is obtained from transfer prices, it is clear that $\pi_{0}^{G}=-c_{0}\left(q_{1}^{G}+q_{2}^{G}\right)-B_{0}^{G}$. Hence,

$\left(T P_{1}\right)\left(q_{1}^{G}\right)+\left(T P_{2}\right)\left(q_{2}^{G}\right)-c_{0}\left(q_{1}^{G}+q_{2}^{G}\right)-B_{0}^{G}=\phi_{0}$. 
Therefore, the supplier's expected profit, which is on the left-hand side of the above equation, is also equal to its Shapley value from game $(3 ; v)$.

\subsubsection{The case of one-member coalitions}

Here, no coalition is formed among the three players. In this case, each retailer chooses his order quantity to maximize his own profits and the supplier would deliver the amount ordered by the retailers for a wholesale price $p_{0}$. Each retailer faces a newsvendor problem. That is,

$\operatorname{Max} \pi_{i}\left(q_{i}\right)=E\left[p_{i} \min \left(q_{i}, D_{i}\right)-\eta_{i}\left(\left[D_{i}-q_{i}\right]^{+}\right)-h_{i}\left(\left[q_{i}-D_{i}\right]^{+}\right)-B_{i}-p_{0} q_{i}\right]$

where $i=1,2$ and $\left[D_{i}-q_{i}\right]^{+}=\left\{\begin{array}{ccc}D_{i}-q_{i} & \text { if } & \left(D_{i}-q_{i}\right) \geq 0 \\ 0 & \text { if } & \left(D_{i}-q_{i}\right)<0\end{array}\right.$.

Suppose the optimal order quantities of $R_{i}(i=1,2)$ are $q_{1}{ }^{N}$ and $q_{2}{ }^{N}$, respectively (Refer Section 4.3.4 for the evidence of the existence and uniqueness of $q_{1}^{N}$ and $q_{2}{ }^{N}$ ). Then the worth of $R_{i}$ is as follows, $v\left(R_{i}\right)=\pi_{i}\left(q_{i}^{N}\right)$.

With the optimal order quantity, $q_{1}^{N}$, the total payment of $R_{1}$ to $R_{0}$ is $p_{0} q_{1}^{N}$ and the resulting order fixed cost of $R_{0}$ is $B_{0}$. Let the profit of $R_{0}$ resulting from $R_{1}$ be $\pi_{0_{1}}$, then $\pi_{0_{1}}=p_{0} q_{1}^{N}-B_{0}$. Regarding a transaction of $R_{0}$ with $R_{2}$, similarly, the total payment of $R_{2}$ to $R_{0}$ is $p_{0} q_{2}^{N}$ with an optimal order quantity, $q_{2}{ }^{N}, \pi_{0_{2}}=p_{0} q_{2}^{N}-B_{0}$. Hence the revenue of $R_{0}$ is $p_{0} q_{1}^{N}+p_{0} q_{2}^{N}$ and the cost of $R_{0}$ is $B_{0}+B_{0}+c_{0} q_{1}^{N}+c_{0} q_{2}^{N}$. Therefore, the profit function of $R_{0}$ is the sum of profits from transactions with the two retailers

$$
v\left(R_{0}\right)=\pi_{0}=\pi_{0_{1}}+\pi_{0_{2}}=p_{0}\left(q_{1}^{N}+q_{2}^{N}\right)-c_{0}\left(q_{1}^{N}+q_{2}^{N}\right)-2 B_{0}
$$

\subsubsection{The case of two-member coalitions}

There are three scenarios if two of the players are cooperating.

Scenario 1: $R_{1}$ forms a coalition with $R_{0}$, with $R_{2}$ staying isolated.

In this scenario, $R_{1}$ and $R_{0}$ would like to maximize their total profits. The coalition revenue is $p_{1} \min \left(q_{1}, D_{1}\right)$. The total fixed cost is now $B_{01}$, with the assumption of fixed cost saving, $B_{01}<B_{0}+B_{1}$. The manufacturing cost of the order quantity $q_{1}$ is $c_{0} q_{1}$. Then

$$
\operatorname{Max} \pi_{01}\left(q_{1}\right)=E\left[p_{1} \min \left(q_{1}, D_{1}\right)-\eta_{1}\left(\left[D_{1}-q_{1}\right]^{+}\right)-h_{1}\left(\left[q_{1}-D_{1}\right]^{+}\right)-B_{01}-c_{0} q_{1}\right]
$$

Let $q_{1}^{S}$ denote the order quantity when $\pi_{01}\left(q_{1}\right)$ is maximized (refer Section 4.3.4 for the existence and uniqueness of $q_{1}^{S}$ ). The payoff of $R_{2}$ is the same as in Section 4.3.1, since $R_{2}$ orders to optimize his own profits. Therefore, the worth of the coalition composed of $R_{1}$ and $R_{0}, v\left(R_{0} R_{1}\right)$, is $v\left(R_{0} R_{1}\right)=\pi_{01}\left(q_{1}^{S}\right)+\pi_{0_{2}}$.

Except the payoff of the coalition $R_{0}$ and $R_{1}, R_{0}$ would get some profits from transactions with $R_{2}$, even without any agreement between $R_{0}$ and $R_{2}$. 
Scenario 2: $R_{2}$ forms a coalition with $R_{0}$, with $R_{1}$ staying isolated.

Similarly, we would like to maximize the expected profit function of the coalition of $R_{0}$ and $R_{2}$ by

Max $\pi_{02}\left(q_{2}\right)=E\left[p_{2} \min \left(q_{2}, D_{2}\right)-\eta_{2}\left(\left[D_{2}-q_{2}\right]^{+}\right)-h_{2}\left(\left[q_{2}-D_{2}\right]^{+}\right)-B_{02}-c_{0} q_{2}\right]$

Let $q_{2}^{S}$ denote the order quantity when $\pi_{02}\left(q_{2}\right)$ is maximized (Refer Section 4.3.4 for the evidence of the existence and uniqueness of $q_{2}^{s}$ ). The payoff of $R_{1}$ is the same as in Section 4.3.1, since $R_{1}$ orders to optimize his own profits. Therefore, the worth of the coalition composed of $R_{2}$ and $R_{0}$ is $v\left(R_{0} R_{2}\right)=\pi_{02}\left(q_{2}^{S}\right)+\pi_{0_{1}}$.

Scenario 3: A coalition composed of $R_{1}$ and $R_{2}$, with $R_{0}$ staying isolated.

If $R_{1}$ and $R_{2}$ form a coalition, we assume they will place an order together and share one common warehouse. The fixed ordering cost is reasonably assumed to be less than the sum of their individual fixed costs: $B_{12}<B_{1}+B_{2}$. The common unit holding cost is reduced and less than their individual unit holding costs: $h<\min \left(h_{1}, h_{2}\right)$.

$$
\begin{aligned}
\operatorname{Max} \pi_{12}\left(q_{1}, q_{2}\right)= & E\left[\sum_{i=1,2} p_{i} \min \left(q_{i}, D_{i}\right)-\sum_{i=1,2} \eta_{i}\left(\left[D_{i}-q_{i}\right]^{+}\right)-h\left(\left[\left(q_{1}+q_{2}\right)-\left(D_{1}+D_{2}\right)\right]^{+}\right)\right] \\
& -B_{12}-p_{0}\left(q_{1}+q_{2}\right) .
\end{aligned}
$$

Let $q_{1}^{R}$ and $q_{2}^{R}$ denote the order quantity when $\pi_{12}\left(q_{1}, q_{2}\right)$ is maximized (Refer section 4.3 .4 for the evidence of the existence and uniqueness of $q_{1}^{R}$ and $\left.q_{2}^{R}\right)$. The worth of the coalition, $v\left(R_{1} R_{2}\right)$, is $v\left(R_{1} R_{2}\right)=\pi_{12}\left(q_{1}^{R}, q_{2}^{R}\right)$.

\subsubsection{The case of the grand coalition}

In the grand coalition, the two retailers would place an order together to the supplier and share one common warehouse. The order quantity is the sum of their individual orders but would optimize the payoff of the grand coalition. Recall that $B_{G}<B_{0}+B_{12}<B_{0}+B_{1}+B_{2}$. To get the optimal order quantity of retailer $i(i=1,2) \quad q_{i}{ }^{G} \quad$ (Refer Section 4.3.4 for the evidence of the existence and uniqueness of $q_{i}{ }^{G}$ ), we would like to maximize the expected profit function of the grand coalition:

$$
\begin{aligned}
\max \pi_{G}\left(q_{1}, q_{2}\right)= & E\left[\sum_{i=1,2} p_{i} \min \left(q_{i}, D_{i}\right)-\sum_{i=1,2} \eta_{i}\left(\left[D_{i}-q_{i}\right]^{+}\right)-h\left(\left[q_{1}+q_{2}-\left(D_{1}+D_{2}\right)\right]^{+}\right)\right] \\
& -B_{G}-c_{0}\left(q_{1}+q_{2}\right) .
\end{aligned}
$$

The worth of the grand coalition, $v\left(R_{0} R_{1} R_{2}\right)$, is

$v\left(R_{0} R_{1} R_{2}\right)=\pi_{G}\left(q_{1}^{G}, q_{2}^{G}\right)$.

\subsubsection{Solutions of the mathematical models}

Eqs. (3-6) are all typical newsvendor problems (Nahmias, 2004). Regarding Eq. (3) 
$\pi_{i}=E\left[p_{i} \min \left(q_{i}, D_{i}\right)-\eta_{i}\left(\left[D_{i}-q_{i}\right]^{+}\right)-h_{i}\left(\left[q_{i}-D_{i}\right]^{+}\right)-B_{i}-p_{0} q_{i}\right]$.

Then

$\frac{d \pi_{1}}{d q_{1}}=p_{1}\left(1-F_{1}\left(q_{1}\right)\right)+\eta_{1}\left(1-F_{1}\left(q_{1}\right)\right)-h_{1} F_{1}\left(q_{1}\right)-p_{0}$, and

$\frac{d^{2} \pi_{1}}{d q_{1}^{2}}=\left(-h_{1}-\eta_{1}-p_{1}\right) f_{1}\left(q_{1}\right)$.

Since $f_{1}\left(q_{1}\right)>0, \frac{d^{2} \pi_{1}}{d q_{1}^{2}}<0$. Thereafter, the optimal order quantity $q_{1}^{N}$ is obtained when $\frac{d \pi_{1}}{d q_{1}}=0$

Rearranging terms gives

$F_{1}\left(q_{1}^{N}\right)=\frac{p_{1}-p_{0}+\eta_{1}}{p_{1}+h_{1}+\eta_{1}}$

Eq. (9) gives the rule to acquire the optimal order quantity $q_{1}^{N}$. Since $p_{1}>p_{0}>0$ and $\eta_{1}>0$, then $p_{1}-p_{0}+\eta_{1}>0$ and $\frac{p_{1}-p_{0}+\eta_{1}}{p_{1}+h_{1}+\eta_{1}}>0$; since $p_{1}-p_{0}+\eta_{1}<p_{1}+\eta_{1}<p_{1}+h_{1}+\eta_{1}, \frac{p_{1}-p_{0}+\eta_{1}}{p_{1}+h_{1}+\eta_{1}}<1$. Then there must exist one $q_{1}^{N}$, which satisfies Eq. (9). In addition, with the monotonicity of a cumulative distribution function $F_{1}(\cdot)$, the optimal order quantity $q_{1}^{N}$ is unique.

Similarly for $R_{2}$, to determine the value of $q_{2}$ that maximizes the profit of $R_{2}, v\left(R_{2}\right)$, there must exist one $q_{2}^{N}$, which satisfies Eq. (3) and the optimal order quantity $q_{2}^{N}$ is unique. $q_{2}^{N}$ is reached when $F_{2}\left(q_{2}^{N}\right)=\frac{p_{2}-p_{0}+\eta_{2}}{p_{2}+h_{2}+\eta_{2}}$

The same actions are executed on Eq. (5) to determine the value of $q_{1}$ that maximizes the profit of $R_{1}$ and $R_{0}, v\left(R_{0} R_{1}\right)$ :

$$
\pi_{01}=E\left[p_{1} \min \left(q_{1}, D_{1}\right)-\eta_{1}\left(\left[D_{1}-q_{1}\right]^{+}\right)-h_{1}\left(\left[q_{1}-D_{1}\right]^{+}\right)-B_{01}-c_{0} q_{1}\right] .
$$

It will be maximized when

$F_{1}\left(q_{1}^{S}\right)=\frac{p_{1}-c_{0}+\eta_{1}}{p_{1}+h_{1}+\eta_{1}}$

Since $p_{1}>p_{0}>c_{0}>0$ and $\eta_{1}>0$, then $p_{1}-c_{0}+\eta_{1}>0$ and $\frac{p_{1}-c_{0}+\eta_{1}}{p_{1}+h_{1}+\eta_{1}}>0$; since $p_{1}-c_{0}+\eta_{1}<p_{1}+\eta_{1}$ $<p_{1}+h_{1}+\eta_{1}, \frac{p_{2}-p_{0}+\eta_{2}}{p_{2}+h_{2}+\eta_{2}}<1$. Then there must exist one $q_{1}^{s}$, which satisfies Eq. (10). In addition, with the monotonicity of a cumulative distribution function $F_{1}(\cdot)$, the optimal order quantity $q_{1}^{S}$ is unique. Hence $q_{1}^{S}$ is reached where the demand cumulative distribution function equals to the fraction $\frac{p_{1}-c_{0}+\eta_{1}}{p_{1}+h_{1}+\eta_{1}}$

Similarly we can determine the value of $q_{2}$ that maximizes the profit of $R_{2}$ and $R_{0}, v\left(R_{0} R_{2}\right)$, using Eq. (6). There exists a unique optimal order quantity $q_{2}^{S}$, satisfying $F_{2}\left(q_{2}{ }^{S}\right)=\frac{p_{2}-c_{0}+\eta_{2}}{p_{2}+h_{2}+\eta_{2}}$. 
Eqs. (7-8) are not typical newsvendor problems, each with two variables. However, the value of $q_{1}$ and $q_{2}$ can be determined simultaneously that maximize the payoff of the coalition consisting of $R_{1}$ and $R_{2}, \pi_{12}$ :

$$
\pi_{12}=E\left[\sum_{i=1,2} p_{i} \min \left(q_{i}, D_{i}\right)-\sum_{i=1,2} \eta_{i}\left(\left[D_{i}-q_{i}\right]^{+}\right)-h\left(\left[\left(q_{1}+q_{2}\right)-\left(D_{1}+D_{2}\right)\right]^{+}\right)\right]-B_{12}-p_{0}\left(q_{1}+q_{2}\right) .
$$

Since demands are following normal distribution functions, the sum of two normal random variable, $Z$, is still following a normal distribution, $g(z)$. Here, $E[Z]=E\left[D_{1}\right]+E\left[D_{2}\right]$ and $\operatorname{Var}(Z)$ $=\operatorname{Var}\left(D_{1}\right)+\operatorname{Var}\left(D_{2}\right)$.

$\frac{\partial \pi_{12}}{\partial q_{1}}=p_{1}\left(1-F_{1}\left(q_{1}\right)\right)+\eta_{1}\left(1-F_{1}\left(q_{1}\right)\right)-h G\left(q_{1}+q_{2}\right)-p_{0}$, and

$\frac{\partial \pi_{12}}{\partial q_{2}}=p_{2}\left(1-F_{2}\left(q_{2}\right)\right)+\eta_{2}\left(1-F_{2}\left(q_{2}\right)\right)-h G\left(q_{1}+q_{2}\right)-p_{0}$.

$\frac{\partial^{2} \pi_{12}}{\partial q_{1}^{2}}=-\left(p_{1}+\eta_{1}\right) f_{1}\left(q_{1}\right)-h g\left(q_{1}+q_{2}\right)$

$\frac{\partial^{2} \pi_{12}}{\partial q_{2}^{2}}=-\left(p_{2}+\eta_{2}\right) f_{2}\left(q_{2}\right)-h g\left(q_{1}+q_{2}\right)$, and

$\frac{\partial^{2} \pi_{12}}{\partial q_{1} q_{2}}=-h g\left(q_{1}+q_{2}\right)$.

Since $\frac{\partial^{2} \pi_{12}}{\partial q_{1}{ }^{2}} \frac{\partial^{2} \pi_{12}}{\partial q_{2}{ }^{2}}-\left(\frac{\partial^{2} \pi_{12}}{\partial q_{1} q_{2}}\right)^{2}>0$, and $\frac{\partial^{2} \pi_{12}}{\partial q_{1}{ }^{2}}<0$, the optimal order quantity $q_{1}^{R}$ of $R_{1}$ and $q_{2}^{R}$ of $R_{2}$ can be obtained when $\frac{\partial \pi_{12}}{\partial q_{1}}=0$, and $\frac{\partial \pi_{12}}{\partial q_{2}}=0$. Rearranging terms gives

$\left(p_{1}+\eta_{1}\right)\left(1-F_{1}\left(q_{1}^{R}\right)\right)-h G\left(q_{1}^{R}+q_{2}^{R}\right)=p_{0}$, and

$\left(p_{2}+\eta_{2}\right)\left(1-F_{2}\left(q_{2}^{R}\right)\right)-h G\left(q_{1}^{R}+q_{2}^{R}\right)=p_{0}$.

$q_{1}^{R}$ and $q_{2}^{R}$ determined by Eq. (11) and Eq. (12) simultaneously are used as the optimal order quantity of $R_{1}$ and $R_{2}$ when they form a coalition. Next, we will show the existence and uniqueness of $q_{1}^{R}$ and $q_{2}^{R}$. Because $0 \leq G(\cdot) \leq 1,\left(p_{1}+\eta_{1}\right)\left(1-F_{1}\left(q_{1}^{R}\right)\right) \geq p_{0}$ and $\left(p_{1}+\eta_{1}\right)\left(1-F_{1}\left(q_{1}^{R}\right)\right) \leq p_{0}+h$. With $p_{1}>p_{0}$ and $\eta_{1}>h, \quad F_{1}\left(q_{1}^{R}\right)<1$ and $F_{1}\left(q_{1}^{R}\right)>0$. Similarly, $F_{2}\left(q_{2}^{R}\right)<1$ and $F_{2}\left(q_{2}^{R}\right)>0$. Thus, there must be at least one $q_{1}^{R}$ and $q_{2}^{R}$ satisfy the system of Eqs. (11) and (12). Meanwhile, since $\left(p_{1}+\eta_{1}\right)\left(1-F_{1}\left(q_{1}^{R}\right)\right)=\left(p_{2}+\eta_{2}\right)\left(1-F_{2}\left(q_{2}^{R}\right)\right), \quad F_{1}\left(q_{1}^{R}\right)$ and $F_{2}\left(q_{2}^{R}\right)$ have a positive linear relationship. With the increasing monotonicity of cumulative distribution functions, $F_{1}(\cdot)$ and $F_{2}(\cdot), q_{1}^{R}$ and $q_{2}^{R}$ have a monotonically increasing relationship. Furthermore, the cumulative distribution function $G(\cdot)$ is also a monotonically increasing function. Since Eq. (11) and Eq. (12) can be further written as

$$
\begin{aligned}
& p_{1}+\eta_{1}-p_{0}=\left(p_{1}+\eta_{1}\right) F_{1}\left(q_{1}^{R}\right)+h G\left(q_{1}^{R}+q_{2}^{R}\right) \text { and } \\
& p_{2}+\eta_{2}-p_{0}=\left(p_{2}+\eta_{2}\right) F_{2}\left(q_{2}^{R}\right)+h G\left(q_{1}^{R}+q_{2}^{R}\right),
\end{aligned}
$$


there is at most one set of solutions that could satisfy Eq. (11) and Eq. (12). Suppose there is one set of solutions $q_{1}$ and $q_{2}$, no matter increasing $q_{1}$ and $q_{2}$ or decreasing $q_{1}$ and $q_{2}$ will not make the previous two equations balance any more. So far, the existence and uniqueness of the solution to the system Eq. (11) and Eq. (12) have been proved. Eq. (8) is also a maximizing problem with two variables. Similarly, there exist a unique solution $q_{1}^{G}$ and $q_{2}^{G}$ to maximize Eq. (8), satisfying

$$
\begin{aligned}
& \left(p_{1}+\eta_{1}\right)\left(1-F_{1}\left(q_{1}^{G}\right)\right)-h G\left(q_{1}^{G}+q_{2}^{G}\right)=c_{0}, \quad \text { and } \\
& \left(p_{2}+\eta_{2}\right)\left(1-F_{2}\left(q_{2}^{G}\right)\right)-h G\left(q_{1}^{G}+q_{2}^{G}\right)=c_{0} .
\end{aligned}
$$

Accordingly, retailer 1 and retailer 2's expected profits with the grand coalition are as follows

$$
\begin{aligned}
& \pi_{1}^{G}=E\left[p_{1} \min \left(q_{1}^{G}, D_{1}\right)-\eta_{1}\left(\left[D_{1}-q_{1}^{G}\right]^{+}\right)-h\left(\left[q_{1}^{G}-D_{1}\right]^{+}\right)\right]-B_{1}^{G}, \text { and } \\
& \pi_{2}^{G}=E\left[p_{2} \min \left(q_{2}^{G}, D_{2}\right)-\eta_{2}\left(\left[D_{2}-q_{2}^{G}\right]^{+}\right)-h\left(\left[q_{2}^{G}-D_{2}\right]^{+}\right)\right]-B_{2}^{G} .
\end{aligned}
$$

\subsubsection{The transfer pricing problem}

Next transfer prices will be set between the supplier and each retailer to allocate the costs and revenue. With the assumption of subadditive cost function, the game by $R_{0}, R_{1}$ and $R_{2}$ is convex with a non-empty core (Rosenthal, 2008). Hence there exists at least one solution that satisfies the conditions of the core. The Shapley value allocation is the centroid of the core set in a convex game (Shapley, 1971). The core allocation insures that the total payoff of the grand coalition is split among all the players, and the sum of the payoffs to the players of each coalition $S$ is not less than the payoff of the coalition $S$. With an allocation in the core of a game, no player can get more without lowering other's payoff. The Shapley value is the unique payoff division that divides the payoff of the grand coalition and satisfies the four mentioned axioms. The Shapley value solution (Eq. 2) is thus used as our profit division rule to set fair transfer prices. the Shapley values of $R_{0}, R_{1}$, and $R_{2}$ can be obtained as follows, respectively:

$$
\begin{aligned}
& \phi_{1}=\frac{1}{3} \pi_{1}+\frac{1}{6}\left(\pi_{12}-\pi_{2}\right)+\frac{1}{6}\left(\pi_{01}+\pi_{0_{2}}-\pi_{0}\right)+\frac{1}{3}\left(\pi_{G}-\pi_{02}-\pi_{0_{1}}\right), \\
& \phi_{2}=\frac{1}{3} \pi_{2}+\frac{1}{6}\left(\pi_{12}-\pi_{1}\right)+\frac{1}{6}\left(\pi_{02}+\pi_{0_{1}}-\pi_{0}\right)+\frac{1}{3}\left(\pi_{G}-\pi_{01}-\pi_{0_{2}}\right), \\
& \phi_{0}=\frac{1}{3} \pi_{0}+\frac{1}{6}\left(\pi_{01}+\pi_{0_{2}}-\pi_{1}\right)+\frac{1}{6}\left(\pi_{02}+\pi_{0_{1}}-\pi_{2}\right)+\frac{1}{3}\left(\pi_{G}-\pi_{12}\right) .
\end{aligned}
$$

The following steps are to allocate the fixed cost of the grand coalition among the three players by the Shapley value:

$$
\begin{aligned}
& B_{1}^{G}=\frac{1}{3} B_{1}+\frac{1}{6}\left(B_{12}-B_{2}\right)+\frac{1}{6}\left(B_{01}-B_{0}\right)+\frac{1}{3}\left(B_{012}-B_{02}\right), \\
& B_{2}^{G}=\frac{1}{3} B_{2}+\frac{1}{6}\left(B_{12}-B_{1}\right)+\frac{1}{6}\left(B_{02}-B_{0}\right)+\frac{1}{3}\left(B_{012}-B_{01}\right), \text { and } \\
& B_{0}^{G}=\frac{1}{3} B_{0}+\frac{1}{6}\left(B_{01}-B_{1}\right)+\frac{1}{6}\left(B_{02}-B_{2}\right)+\frac{1}{3}\left(B_{012}-B_{12}\right) .
\end{aligned}
$$

Now the transfer price between $R_{0}$ and $R_{1}, T P_{1}$, can be set as 
$T P_{1}=\frac{\pi_{1}^{G}-\phi_{1}}{q_{1}^{G}}$, or

$\left(T P_{1}\right)\left(q_{1}^{G}\right)=E\left[p_{1} \min \left(q_{1}^{G}, D_{1}\right)-\eta_{1}\left(\left[D_{1}-q_{1}^{G}\right]^{+}\right)-h\left(\left[q_{1}^{G}-D_{1}\right]^{+}\right)\right]-B_{1}^{G}-\phi_{1}$.

Similarly, we get the transfer price, $T P_{2}$, between $R_{0}$ and $R_{2}$

$T P_{2}=\frac{\pi_{2}^{G}-\phi_{2}}{q_{2}^{G}}$, or

$\left(T P_{2}\right)\left(q_{2}^{G}\right)=E\left[p_{2} \min \left(q_{2}^{G}, D_{2}\right)-\eta_{2}\left(\left[D_{2}-q_{2}^{G}\right]^{+}\right)-h\left(\left[q_{2}^{G}-D_{2}\right]^{+}\right)\right]-B_{2}^{G}-\phi_{2}$.

\subsection{A numerical example}

The numerical example is designed to show the whole methodology procedure associated with transfer pricing assuming normal demand distribution functions. For each coalition of three players, the profit functions can be obtained following the suggested solution in Section 4.3.4. With the profit functions, the Shapley value Eq. (2) is then used to reach the ideal transfer prices between retailers and the supplier. Demands to retailer 1 and retailer 2 are both normally distributed, defined as $D_{1}$ and $D_{2}$, with $D_{1} \sim N(1000,200)$ and $D_{2} \sim N(800,150)$. Then $D_{1}+D_{2} \sim N(1800,250)$. Other parameters are assigned as follows: $B_{1}=\$ 100 ; B_{2}=\$ 80 ; h_{1}=\$ .6 /$ unit $; h_{2}=\$ .8 /$ unit $; \eta_{1}=\$ 1.2 ; \eta_{2}=\$ 1$; $p_{1}=\$ 10 ; p_{2}=\$ 11 ; c_{0}=\$ 2 ; p_{0}=\$ 5 ; B_{0}=\$ 150 ; B_{01}=\$ 120 ; B_{02}=\$ 100 ; B_{12}=\$ 80 ; B_{G}=\$ 125 ;$ $h=\$ .3 /$ unit .

By following the procedure suggested in Section 4.3, we get;

$$
\begin{aligned}
& v(1)=\pi_{1}=3961.2 ; v(2)=\pi_{2}=3959.6 ; v(0)=\pi_{0}=5191.3 \\
& v(01)=9484.07 ; v(02)=9420.62 ; v(12)=\pi_{12}=8062.92 \\
& v(012)=\pi_{G}=13942.4 \\
& q_{1}^{G}=1166.72 ; q_{2}^{G}=932.36
\end{aligned}
$$

After Eq. (2) is applied, the Shapley value of each member is computed as $\phi_{1}=4243, \phi_{2}=4208$, and $\phi_{0}=5491$. The highest Shapley value is assigned to the supplier and the reason is that the supplier can earn most even though the supplier remains independent from the grand coalition and his contribution to the grand coalition is the highest among the three. The percentage of profit increases for $R_{1} R_{2} R_{0}$ will be 7.1, 6.3, and 7.6, respectively. Next, Eq. (2) is used to calculate the allocation of fixed costs to each member in the grand coalition: $B_{1}^{G}=36.7, B_{2}^{G}=16.7$, and $B_{0}^{G}=71.7$.

Therefore,

$T P_{1}=\frac{5409.81}{q_{1}^{G}}=4.65$ and $T P_{2}=\frac{4344.2}{q_{2}^{G}}=4.66$.

Comparing with the case without any agreement, the transfer prices are reduced from the $\$ 5$ wholesale price. The retailers are happier about it since they can expect instant profit increase. And the supplier is happier too because even though the unit prices paid by the retailers are reduced, his profit still increases with a significant percentage.

\section{Discussion and Summary}

In this paper, we studied a supply chain with one supplier and two retailers. The research discussed herein contributes to the supply chain transfer pricing literature by relaxing the assumption of 
deterministic demand. The Shapley value solution is explored to obtain a fair sharing of revenues and costs. Even when there are multiple suppliers and retailers, our analysis provides a procedure to follow for supply chain profit division. This paper has shed light on the difficulties in achieving supply chain coordination when retailers face stochastic demands. From a managerial perspective, the transfer prices obtained by this procedure would offer an acceptable suggestion when supply chain members are bargaining on contract agreements. A supply chain contract has been shown to be an effective tool to coordinate supply chains, but how to reach supply chain contract agreements still needs more attention. Since supply chain members are more concerned about their individual profits, the agreements on transfer prices are critical for all members. Given the widely used stochastic demand assumption, the transfer prices obtained by our procedure have the advantage of incorporating practical market demand into a model in profit division. Furthermore, a supply chain contract is difficult to perform if the supply chain members are independent firms. Sometimes legal actions are necessary to ensure performance of a successfully negotiated contract, which results in huge costs and hurts supply chain relationships. However, fairly settled contracts are more likely to be executed by supply chain members.

Distributive decisions involve a variety of factors, and the profit division suggested by the Shapley value may not be accepted by more powerful players since they have power to earn more. The power of a player would affect the player's behavior. It could be true that since powerful players have more resources, they can act at will without causing serious negative outcomes to themselves. Future research can focus more on power in profit allocation: how to measure and assign power among players in supply chains. A natural extension of our model would be to consider profit division among multi-stage supply chain members with coordination. Multi-stage supply chains are widely studied in inventory management (Khouja, 2003), profit division in a constant demand market (Rosenthal, 2008), etc. This multi-stage extension in a stochastic market would bring further realism as it would determine the profit division scheme for a long term relationship, very likely with repeated transactions. Another limitation is about the stochastic demand, which is simply assumed fluctuating as a random variable. More subtly, demand could be a function of retail price in the future, and we can treat the retail price as a decision variable and see how to affect the profit division.

As indicated by Ronchi et al. (2007), supply chain coordination is much less frequently adopted than expected. Probably it results from firm interaction problems, such as lack of mutual trust, conflict of risk and benefit sharing allocation, etc. Our model improves supply chain coordination by providing procedures to set fair transfer prices among individual supply chain members. We believe that the class of problems in transfer pricing for supply chain transactions represents a promising area for future research and practice.

\section{References}

Bartholdi, J.J. and E. Kemahlioğlu-Ziya. (2005). Using Shapley value to allocate savings in a supply chain. J. Geunes, Pardalos P. M. Eds. Supply Chain Optimization, Springer, New York.

Cachon, G. (1999). Competitive supply chain inventory management. Tayur, S., Magazine, M., Ganeshan, R. eds. Quantitative Models for Supply Chain Management. Kluwer Academic Publishers, Norwell, MA.

Cachon, G. (2003). Supply chain coordination with contracts. A.G. de Kok, Stephen C. Graves, editors. The handbook of operations research and management science: supply chain management. Kluwer, Amsterdam, the Netherlands.

Cachon, G. P., \& Lariviere, M. A. (2005). Supply chain coordination with revenue-sharing contracts: strengths and limitations. Management science, 51(1), 30-44.

Feess, E., \& Thun, J. H. (2014). Surplus division and investment incentives in supply chains: A biform-game analysis. European Journal of Operational Research, 234(3), 763-773. 
Fransoo, J. C., Wouters, M. J., \& De Kok, T. G. (2001). Multi-echelon multi-company inventory planning with limited information exchange. Journal of the Operational Research Society, 130(7), 830-838.

Gerchak, Y., \& Gupta, D. (1991). On apportioning costs to customers in centralized continuous review inventory systems. Journal of Operations Management, 10(4), 546-551.

Gjerdrum, J., Shah, N., \& Papageorgiou, L. G. (2002). Fair transfer price and inventory holding policies in two-enterprise supply chains. European Journal of Operational Research, 143(3), 582599.

Granot, D., \& Sošic, G. (2003). A three-stage model for a decentralized distribution system of retailers. Operations Research, 51(5), 771-784.

Khouja, M. (2003). Optimizing inventory decisions in a multi-stage multi-customer supply chain. Transportation Research Part E: Logistics and Transportation Review, 39(3), 193-208.

Manes, R., \& Verrecchia, R. (1982). A new proposal for setting intra-company transfer prices. Accounting and Business Research, 12(46), 97-104.

Nahmias, S. (2004). Production and Operations Analysis. $5^{\text {th }}$ edition. McGraw-Hill/Irwin.

Robinson, L. W. (1993). A comment on Gerchak and Gupta's "On apportioning costs to customers in centralized continuous review inventory systems". Journal of Operations Management, 11(1), 99102.

Ronchi, S., Luzzini, D., \& Spina, G. (2007). Supply chain coordination: The problem of risk and benefit sharing. Supply Chain Forum: International Journal, 8(2), 54-65.

Rosenthal, E. C. (2008). A game-theoretic approach to transfer pricing in a vertically integrated supply chain. International Journal of Production Economics, 115(2), 542-552.

Shapley, L. (1953). A value for n-person games. In: Tucher, A., Kuhn, H. eds. Contributions to the Theory of Games. Princeton University Press, Princeton, NJ.

Shapley, L. S. (1971). Cores of convex games. International journal of game theory, 1(1), 11-26.

Sošic, G. (2006). Transshipment of inventories among retailers: Myopic vs. farsighted stability. Management science, 52(10), 1493-1508.

Vaysman, I. (1998). A model of negotiated transfer pricing. Journal of Accounting and Economics, 25(3), 349-384.

Vidal, C. J., \& Goetschalckx, M. (2001). A global supply chain model with transfer pricing and transportation cost allocation. European Journal of Operational Research, 129(1), 134-158.

Yeom, S., \& Balachandran, K. R. (2000). The role of transfer price for coordination and control within a firm. Review of Quantitative Finance and Accounting, 14(2), 161-192. 